\title{
Molecular signature of cancer stem cells isolated from prostate carcinoma and expression of stem markers in different Gleason grades and metastasis
}

\author{
Enrique A. Castellón ${ }^{1 *}$, Rodrigo Valenzuela ${ }^{1}$, Jorge Lillo ${ }^{1}$, Viviana Castillo ${ }^{1}$, Héctor R. Contreras ${ }^{1}$, Iván Gallegos ${ }^{2}$, \\ Alejandro Mercado ${ }^{1,3}$ and Christian Huidobro ${ }^{1,3}$
}

\author{
1 Physiology and Biophysics Program. Institute of Biomedical Sciences. Faculty of Medicine. University of Chile \\ 2 Pathological Anatomy Service, Clinic Hospital of University of Chile \\ 3 Urology Service, Clinic Hospital of University of Chile
}

\begin{abstract}
Prostate cancer (PCa) is the most frequently diagnosed malignancy in men worldwide. Chemotherapy response is very poor and resistance to hormone-based treatments is frequent in advances stages. Recently, tumor-initiating cells or cancer stem cells (CSCs) have been identified in several cancers, including PCa. These cells are thought to be responsible for therapy resistance, relapse and metastasis. In the present work, enriched populations of CSCs were obtained using a mixed procedure that included differential clone-forming ability, sphere growing induction (prostatospheres) and magnetic-associated cell sorting (MACS). Also, stem marker expression was determined in PCa biopsies of different histological grades and metastasis samples. The signature for stem markers of the isolated CSCs was CD133+/CD44+/ABCG2+/ CD24-. Expression of stem markers (CD133, CD44, and ABCG2) was higher in medium Gleason biopsies than in lower and higher grades, and lymph-node and bone metastasis samples. These results suggest that the CSCs in PCa reach an important number in medium Gleason grades, when the tumor is still confined into the gland. At this stage, the surgical treatment is usually with curative intention. However, an important percentage of patients relapse after treatment. Number and signature of CSCs may be a prognosis factor for PCa recurrence.
\end{abstract}

Key words: prostate cancer, cancer stem cell, spheres cultures

\section{INTRODUCTION}

Prostate cancer (PCa) is the second leading cause of male malignancy death throughout the world (Dunn and Kazer 2011). In Chile, this disease reached that level very rapidly and currently over 1,700 patients die annually due to this cancer, representing an observed rate exceeding 20 per 100,000 men (Minsal 2011). This number may be even underestimated considering that PCa occurs mainly in men over 60 years, where other associated medical conditions may be contributing to the cause of death. If localized, PCa can be cured by surgical treatment. However, more than $30 \%$ of patients may relapse after surgery (Kotb and Elabbady 2011). Once disseminated, PCa can be controlled by hormonal treatment (androgen deprivation) and mortality is primarily associated with metastatic disease when patients become resistant to treatments (hormone therapy, radiotherapy and chemotherapy).

Recent studies on cancer pathogenesis have identified the presence of tumor stem-like cells that could influence the key processes of tumor progression (Clarke et al. 2006; Shipitsin and Polyak 2008). These cells have tumor-initiating and self-renewing abilities, divide asymmetrically, and express several pluripotency genes (La Porta 2012). For these reasons, many authors have called them cancer stem cells (CSCs). In recent years, CSCs were identified in several cancers, including $\mathrm{PCa}$, and have been proposed to explain the metastatic capacity, recurrence, and resistance to hormone, radio and chemotherapy (Gao 2008; Ishii et al. 2008; Li et al. 2007). In established cell lines from PCa origin, particularly from metastasis, CSCs have been identified and isolated using different approaches, such as flow cytometry, magneticassociated cell sorting (MACS), the ability of differential cloning and sphere growing under non-adherent culture conditions (Collins and Maitland 2006; Collins et al. 2005; Miki and Rhim 2008; Miki et al. 2007; Tang et al. 2007). Most of these studies have used cell lines as PC3, DU145, and LNCaP, and animal models. These reports have identified several molecular markers for CSCs such as CD44, CD133, CD24, CD40 and $\alpha 2 \beta 1$ integrin, among others (Patrawala et al. 2007; Pfeiffer and Schalken 2010). In addition, the ability to exclude Hoechst 33342 staining has been widely used for identifying and separating stem cells (side population) (Patrawala et al. 2005; Zhou et al. 2001). The exclusion of this dye is caused by the ABCG2 transporter that is over-expressed in CSCs. The presence of a side population has been also reported in $\mathrm{PCa}$ cells (Pascal et al. 2007). Interestingly, ABC transporters are thought to be responsible for drug resistance in most cancers (Sharom 2008; Stavrovskaya and Stromskaya 2008), including PCa (Sánchez et al. 2009; Sánchez et al. 2011).

In our laboratory we developed cell culture systems from PCa explants to study several aspects of this disease, such as hormone sensitivity, drug resistance and the effect of various compounds with therapeutic potential (Castellón et al. 2005; Castellón et al. 2006; Clementi et al. 2009; Mendoza et al. 2009; Sánchez et al. 2005). The aim of this work was to isolate and characterize CSCs from our tumor explant-derived cultures in order to determine specific molecular stem signatures and to evaluate these markers in relation to Gleason grades 
and metastasis. This analysis may represent an important prognostic tool for metastasis potential, relapse timing and resistance development. In addition, genetic and functional characterization of these CSCs is being carried out in order to identify potential therapeutic targets for the selective elimination of these cells.

\section{MATERIAL AND METHODS}

Prostate cancer tissue

Tumor samples were derived from radical prostatectomies of patients with localized PCa (mostly patient Gleason score 5-6, histological sample Gleason grade 3) from our institutional hospital. Tissue pieces were received in sterile culture medium with RNase inhibitor and then taken to the laboratory in a period no longer than 1 hour after collection. Once in the laboratory, when necessary, soft healthy or hyperplasic tissue was separated from harder cancerous tissue. For control purpose, small pieces of all samples used for cell isolation and cultures were processed for histological diagnosis to confirm Gleason grade. Successful cultures from six surgical pieces were obtained for this work. All protocols of this study were approved by Ethics Committees of the Faculty of Medicine and the clinic hospital of our university.

Isolation and culture of epithelial cells from prostate cancer

Small pieces (1 $\mathrm{mm} 3)$ of PCa tissue underwent enzymatic digestion with collagenase $(2 \mathrm{mg} / \mathrm{ml})$, hyaluronidase and deoxyribonuclease $(0.02 \mathrm{mg} / \mathrm{ml})$. Digestion was carried out at $37^{\circ} \mathrm{C}$ for $10-12$ hours in a shaking water bath. The process was checked every hour in order to separate dispersed stromal cells. After enzymatic digestion, aggregates of epithelial cells were washed with culture medium and plated. These cell aggregates were cultured in Dulbecco MEM/HAM F-12 (1:1) medium supplemented with 10\% FBS in culture bottles. After 2 or 3 days, once cell aggregates had adhered and spread, the medium was changed by a chemically defined medium according to the methods previously described (Castellón et al. 2005; Castellón et al. 2006).

Isolation of prostate cancer stem cells

Prostate CSCs were identified and isolated from tumor explantderived cultures of epithelial cell (2-4 passages), using a combination of methods previously described.

Differential cloning ability: Detached and washed epithelial cells from explant-derived cultures were counted and diluted. 100 cells were taken and suspended in $10 \mathrm{ml}$ of culture medium. Cells were plated by transferring $100 \mathrm{ul}$ of cell dilution in each well of a of 96-well culture plate. The cells were monitored during the first week to observe and characterize the obtained clones and allowed to grow for another week to evaluate and characterize the different clones, namely, holoclones, meroclones and paraclones (Barrandon and Green 1985). To evaluate the morphology of these clones, cells were washed, fixed with cold methanol $100 \%$ and stained with $0.5 \%$ violet crystal / $25 \%$ methanol for 10 minutes.

Sphere growing induction: Cells obtained from the differential cloning cultures were trypsinized and centrifuged at $2000 \mathrm{rpm}$ for 5 minutes. The pellet was suspended and plated, at a density of $4 \times 10^{4}$ cells $/ \mathrm{ml}$, in DMEM medium without FBS and supplemented with the following factors: $5 \mathrm{ug} / \mathrm{ml}$ of human transferrin, $5 \mathrm{ug} / \mathrm{ml}$ of insulin, $20 \mathrm{ng} /$ $\mathrm{ml}$ of EGF, $10 \mathrm{ng} / \mathrm{ml}$ of FGF-2, $200 \mathrm{ng} / \mathrm{ml}$ of retinol, $200 \mathrm{ng} /$ $\mathrm{ml}$ of vitamin E, $10 \mathrm{nM}$ of hydrocortisone, $2 \mathrm{ng} / \mathrm{ml}$ of sodium selenite, and $0.4 \%$ of human serum albumin-free globulins. This culture medium (non-adherent medium) allowed the formation of prostate spheroids (prostatospheres) enriched in CSCs from day 7 of culture (Fan et al. 2010). For control purposes, parallel cultures in adherent conditions were used.

Magnetic-associated cell sorting (MACS): Cell populations enriched in CSCs were dispersed, washed and incubated with antibody-coupled magnetic microbeads for 1 hour. Then, cells were mounted into proper columns and settled in a magnetic support (Pascal et al. 2007). For positive separation, negative cells passed throughout the columns were used as control. Positive retained cells were washed and plated in proper CSCs medium. For negative separation (in case of using a nonstem marker antibody), negative cells were processed as the enriched stem cell population. The selected antibodies coupled to the microbeads for these separations included anti-CD133, anti-CD44, anti-CD24 and anti-ABCG2 (Miltenyi Biotec).

Immunocytochemistry of prostatospheres

Prostatospheres were washed and fixed with paraformaldehyde $10 \%$ in phosphate buffer and then resuspended in HistoGel reagent (Thermo Scientific, HG-4000-012). These structures formed a three-dimensional matrix to preserve the integrity of prostatospheres. Then, the matrix was included in paraffin and sections of 5 um were obtained. Afterwards, samples were deparaffinized with xylene and rehydrated with decreasing ethanol concentrations. Later, sections were incubated for 2 hours with specific antibodies targeting extracellular epitopes of surface proteins CD133 (Miltenyi Biotech.), CD44 (Santa Cruz Biotechnology Inc.), CD24 (Santa Cruz Biotechnology Inc.), ABCG2 (Thermo Scientific) and ALDH2 (Thermo Scientific). After washing to remove non-specifically bound antibody, samples were incubated for 1 hour with secondary biotinylated antibodies followed by peroxidase-labeled streptavidin. Diaminobenzidine was used as chromogen. For immunofluorescence, secondary antibody was conjugated to FITC (Thermo Scientific) and to observe nuclei, DAPI for 5 minutes was used.

Prostate cancer biopsies and metastasis samples

Samples of PCa of different Gleason grades and lymph-node and bone metastases were obtained from our institutional archive of biopsies with the corresponding authorizations. The following samples were used considering the histological grade (Gleason 1 to 5 ) of the biopsies:

Low Gleason (grade 2): 11 samples. Medium Gleason (grade 3): 14 samples. High Gleason (4-5): 9 samples. Lymphnodes metastasis: 7 samples. Bone metastasis: 5 samples.

Immunohistochemistry of prostate cancer biopsies and metastasis samples

Expressions of all markers studied were evaluated by quantitative immunohistochemistry. Only specimens fixed 
and included in optimal conditions for immunohistochemical studies were selected. The samples were deparaffinized and rehydrated. Hydrogen peroxide was used to inactivate endogenous peroxidase activity and antigen retrieval was performed with target retrieval solution. To avoid unspecific binding, samples were incubated with PBS-BSA $1 \%$ for 1 hour at room temperature. Samples were incubated with first antibodies directed against proteins CD133 (Santa Cruz Biotechnology Inc.), CD44 (Santa Cruz Biotechnology Inc.) and ABCG2 (Thermo Scientific) for 1 hour at $37^{\circ} \mathrm{C}$. The signal was amplified using a second biotinylated antibody followed by peroxidase-labeled streptavidin. Diaminobenzidine was used as chromogen. The samples were counterstained with hematoxylin (Ross et al. 2003). All samples were analyzed using Image ProPlus 6.2 software (Media Cybernetics, Bethesda USA), to quantify the immunoreactive area (IA) in $\mathrm{um}^{2}$ and the integrated optical density (IOD), which allows a quantitative densitometric analysis of the specific areas (Ruifrok and Johnston 2001).

\section{Statistic analysis}

Statistic evaluation of data was performed using ANOVA analysis and non-parametric test of Kruskal-Wallis followed by Dunnett's post-test. Statistic significance was considered for $\mathrm{P}<$ 0.05 . Results were expressed as mean \pm SD.

\section{RESULTS}

\section{Enrichment of CSCs by differential cloning ability}

We obtained different clone populations using limiting dilution assays from PCa explant-derived cultures, knowing that CSCs have the ability to form compact colonies. Holoclones (compact colonies), meroclones (loose colonies), and paraclones (dispersed colonies) were obtained from explant-derives cultures (Fig. 1A). From some cultures, more than $35 \%$ of holoclones (Fig. 1B) were yielded. However, it was not possible to obtain compact colonies, with the same expansive characteristics, from all explant-derived cultures (data not shown). These differences could be due to the effect of the number of passages that underwent each culture. It was observed that the greater the number of previous passages of original culture, the higher the holoclones yield. Holoclones obtained by this method showed higher expression of the stem markers than mero- and paraclones. A representative marker (CD44) in shown in Figure 1A and 1C. The successful holoclones maintained their morphological and clonogenic characteristics for at least 3 successive passages (Fig. 2A). However, it should be noted that these clones showed some degree of plasticity, as well as producing primarily holoclones (>90\%), the presence of few mero- and paraclones in the cultures was observed (data not shown).

\section{Enrichment of CSCs by sphere growing induction}

Cells obtained from holoclones were plated under nonadherent condition, knowing that CSCs can survive and aggregate under this condition and generate spheres that grow without differentiation. Successful spheres cultures (prostatospheres) were obtained after a week of culture (Fig. $2 \mathrm{~A}$ and $2 \mathrm{~B}$ ). Some prostatospheres were fixed and processed for immnocytochemistry, showing a molecular signature that included high expression of CD133, CD44, and ABCG2 and no expression of CD24 (Fig. 2B). A few cells of the spheres expressed also ALDH2, another marker described for CSCs. The prostatospheres can be maintained in culture for several weeks without expression of differentiation makers (data not shown).

Enrichment of CSCs by magnetic-associated cell sorting (MACS)

Some prostatospheres were disaggregates and resulting cells washed and processed for MACS separation (see materials and methods). Using the stem markers CD133, CD44 and CD24, further enriched CSCs populations were obtained. In Figure 3 , a representative separation protocol using CD44 is shown. Cells retained in the MACS column (expressing CD44) were washed and plated in proper medium for 48 and $72 \mathrm{hrs}$ (Fig. $3 \mathrm{~A})$. Resulting cultures were enriched over 95\% in CD44expresing cells (Fig. 3B).

Expression of CSCs markers in PCa biopsies of different histological grades and metastasis samples

In order to evaluate the expression of the stem markers described for CSCs isolated from explant-derived cultures in tumor progression and metastasis, we analysed a collection of biopsies of low, medium and high Gleason grade and samples from lymph-node and bone metastasis by immunohistochemistry. Expression of stem markers CD133, CD44 (Fig. 4A), and ABCG2 (Fig. 5A) was observed in all samples. For the three markers studied, medium Gleason biopsies showed the highest expression (Figs. 4B and 5B). Interestingly, lymph-node and bone metastasis showed the lowest expression of CSCs proteins. Tissue for benign prostatic hyperplasia (BPH) was used as non-malignant control. As expected, low expression of stem markers were found in $\mathrm{BPH}$ (Figs. 5 and 6). It is known that in normal prostate CD44 is restricted to basal cells and ABCG2 to endothelial cells.

\section{DISCUSSION}

Stem cells are defined upon their self-renewal capacity and the ability to give rise to complete tissues, organs or even individuals (i.e. embryonic stem cells) (Glinsky 2008; Reya et al. 2001; Visvader and Lindeman 2008). Nearly a decade ago, evidence about the existence of CSCs came from haematopoietic cancers (Bonnet and Dick 1997; Lapidot et al. 1994). In the same way that normal stem cells can give rise to normal tissue or organs, CSCs can give rise to malignant tissue or tumors. Considering that the mechanisms underlying cancer initiation and development remain unclear, the presence of CSCs in most cancers has focussed attention on the role of these cells in carcinogenesis (Cabanillas and Llorente 2009). The identification of CSCs has challenged the hypothesis of "clonal evolution" for cancer development and may implicate new approaches for cancer therapy (Filip 2008; Gil 2008; Lewis 2008). It is still not clear whether CSCs originate from malignant transformation of normal stem cells, or if malignant cells acquire stem characteristics through the epithelial-mesenchymal transition (EMT) (Lobo et al. 2007; Ward and Dirks 2007). Most evidence suggests that cancer originate from progenitor cells rather than stem cells (Pardal et al. 2003; Wicha et al. 2006). There is still debate regarding 
the existence of an actual stem cell in cancer. For these reasons, some authors prefer to refer to these cells as tumor-initiating cells (TICs). Probably, as part of EMT, a small cell population re-expresses some pluripotency genes. These cell populations, with acquired "stemness" features, can be considered as cancer stem-like cells or CSCs.

It is believed that malignant cells undergoing EMT become aggressive due to invading and migrating abilities. They could invade the surrounding stroma, enter lymph and blood circulation and produce local and distant metastases. It is assumed that solid tumors are a rather homogeneous group of cells with high proliferative and invasive capacity and, in a stochastic way, some of these cells leave the tumor and produce metastasis. This explains that most treatments are focussed on eliminating the bulk of these cells (Le Tourneau et al. 2008). However, the presence of a small number of CSCs in many cancers makes it necessary to re-consider that view. Current evidence suggests that CSCs are really responsible for metastasis, recurrence and drug resistance (Borst et al. 2007; Chiang and Massagué 2008; Croker and Allan 2008). Prostate CSCs has been also identified. There have been successful efforts to isolate and characterize PCa CSCs from established cell lines (mainly PC3, LNCaP and DU145) (Celià-Terrassa et al. 2012; Duhagon et al. 2010; Li et al 2008; Setoguchi et al. 2004; Tang et al. 2007). This is a very interesting finding since cell lines have been believed to be very homogeneous
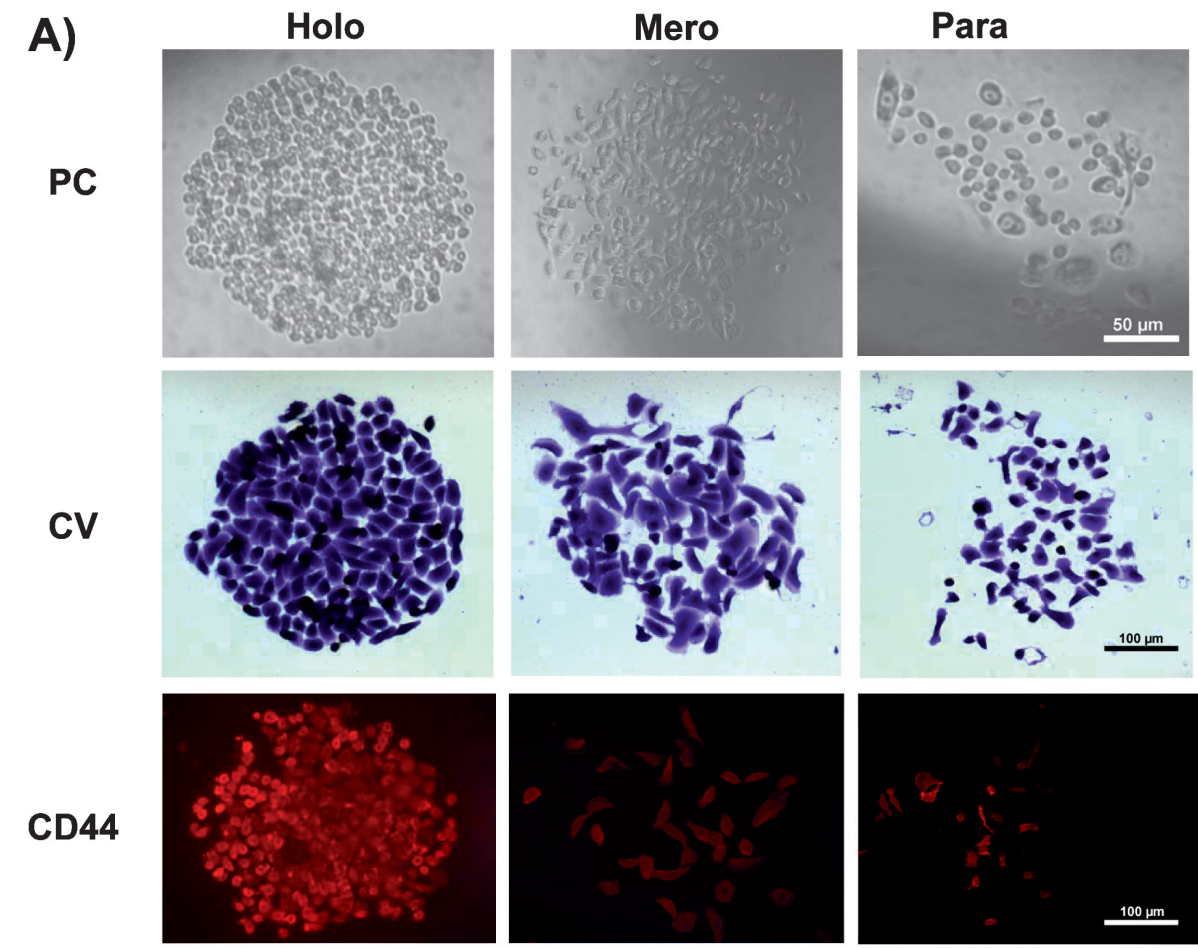

DAPI
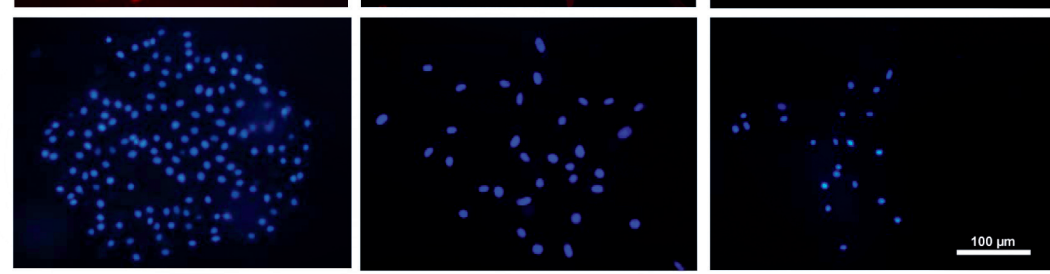

B)

\begin{tabular}{|c|c|c|}
\hline Type of clone & $\mathbf{N}^{0}$ of clones & Percentage \\
\hline Holo & 13 & 36 \\
\hline Mero & 17 & 47 \\
\hline Para & 6 & 17 \\
\hline Total & 46 & 100 \\
\hline
\end{tabular}

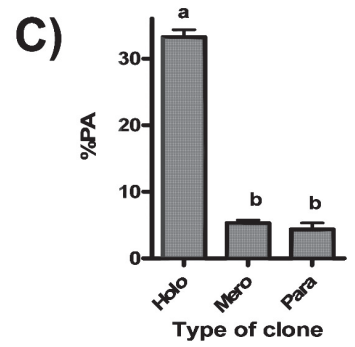

Figure 1. Prostate cancer cell clones obtained by limiting dilution assays. A) Representative images of clones with different morphology. Holo: holoclone, Mero: meroclone, Para: paraclone observed by phase-contrast light microscopy (PC) and stained with crystal violet (CV). A set of clones showing immunofluorescence (red) staining for a representative stem marker (CD44). DAPI (blue) was used for nuclei staining. B) Number and percentage of clones obtained by limiting dilution assay. C) Quantitative analysis of immunofluorescence. Data are expressed as percentage of positive area (PA). Different superscripts represent statistical significance $(p<0.05)$. 
populations. Apparently, they are not, distinguishing at least two very different cell types, one of them CSCs (Celià-Terrassa et al. 2012). Many authors report molecular signatures for these CSCs isolated from cell lines. Most of them are coincident with high expression of the markers CD133, CD44, CD40 and $\alpha 2 \beta 1$ integrin, among others (Yu et al. 2012). Interestingly, some of these markers are also common with CSCs from other solid tumors (La Porta 2012). However, the remaining CSC populations in cancer cell lines may not represent actual CSCs from tumors. Phenotypic, functional and gene expression characteristics may differ substantially. Indeed, there is still uncertainty about the source of CSCs in PCa. Evidence supports both basal and luminal cell compartments as potential prostatic niche for CSCs (Yu et al, 2012). Considering that PCa is a heterogeneous and multi-focal disease, malignant cells may come from different stem sub-populations. In order to address this problem, we have isolated and partially characterized a CSCs population from explant-derived cell cultures from PCa tumors, using combined methods. We were able to obtain enriched cultures of CSCs expressing a consistent molecular signature displaying a CD133+/CD44+/ABCG2+/ CD24- pattern, from these explant-derived cell cultures. Interestingly, this stem signature is similar to those obtained from PCa cell lines (Yu, et al 2012), suggesting that prostate CSCs are very conservative.

Keeping in mind that prostate CSCs could represent a potential therapeutic target (Lang et al. 2009), we evaluated the stem signature described in enriched population of CSCs from tumors, in representative biopsies of the different histological grades and lymph-node and bone metastasis samples. We found, that all stem markers studied were present in low, medium and high Gleason grades and metastasis. However, the highest expression of CSCs proteins was observed in biopsies of medium grades. These samples correspond to patients with medium Gleason score (grades 5 to 6 ). At this stage, the tumor is usually confined to the prostate gland and most patients are subjected to radical surgery. However, many of them (around 30\%) relapse months after surgery (Kotb and Elabbady 2011). This is a very interesting point, considering that metastasis is a very inefficient process, due to less than $1 \%$ of the neoplastic cells reaching blood circulation can actually colonize distant organs, and even a smaller percentage produce metastases (Chiang and Massagué 2008). It is well known that primary tumors secrete signals (altered proteins) that affect, in a selective way, specific stromal tissue favouring CSCs niche (Chiang and Massagué 2008; Witz 2008). Once CSCs colonize these conditioned stromas, they may remain for long periods of time in a dormant state before activating and producing metastases (Kaplan et al. 2006; Wels et al. 2008). This may explain the recurrence after apparently curative surgery in many cancers. In PCa, when a tumor is diagnosed as localized and without clinically evident metastases (medium Gleason grades), it is believed that radical surgery is curative. However, at this stage many cancer cells may have reached blood circulation (according to our results, some of them presumably CSCs), colonized lymph nodes or other tissues and entered

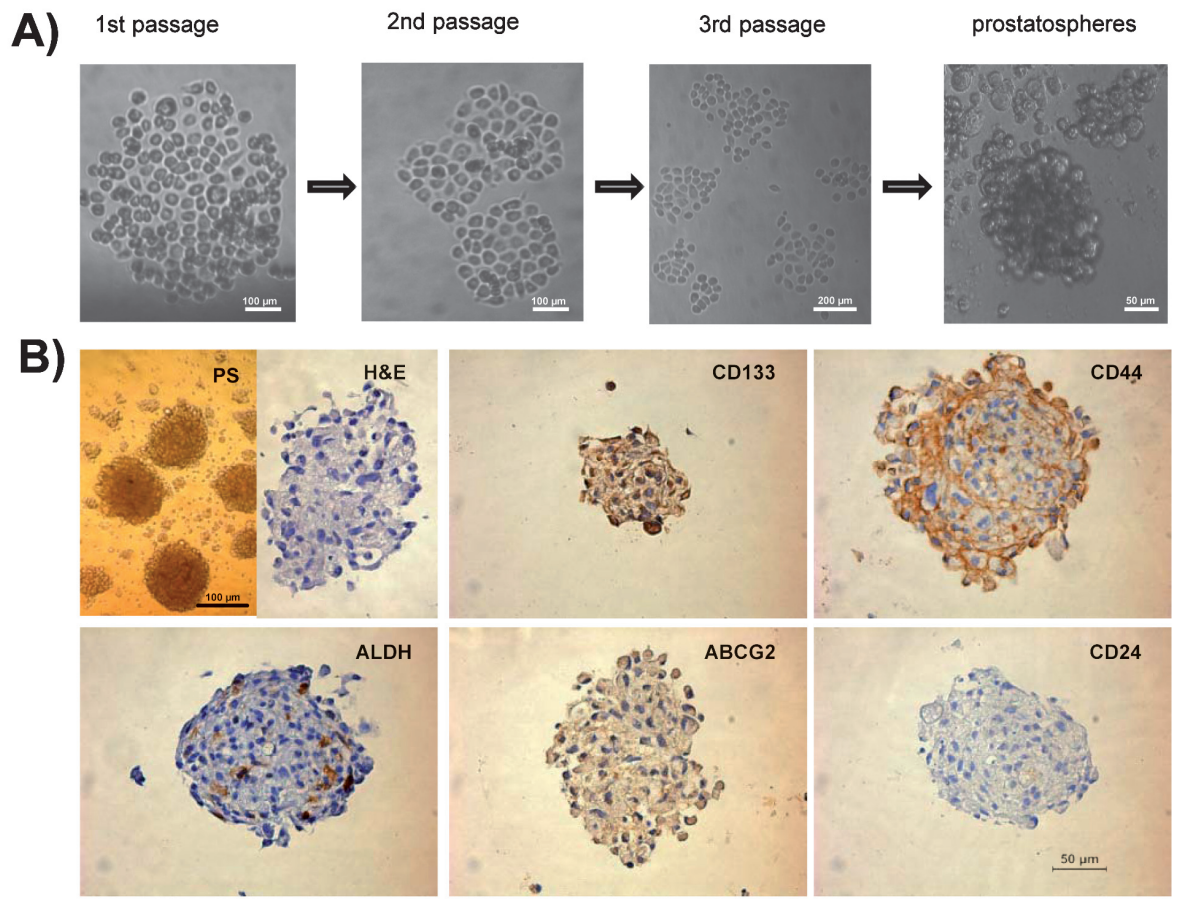

Figure 2. Holoclones sub-cultures and characterization of holoclone-derived spheres. A) Sequence of 3 successive passages of a representative holoclone and representative cell spheroids (prostatospheres) generated from the 3rd passage of holoclones. During the period of time taken by the sequence of passages (approximately 3 weeks) no changes in characteristic morphology was observed. B) Immunocytochemistry analysis of prostate cancer spheres enriched in cancer stem cells. Spheres were fixed, embedded in HistoGel (see materials and methods) and included in paraffin. H\&E: Control Hematoxylin/Eosin staining. 5 um sections were immunocytochemically analyzed for CD133, CD44, ALDH2, ABCG2 and CD24. The main molecular signature observed was CD133+/CD44+/ABCG2+/CD24-. A few cells within prostatospheres were positive for ALDH2. Insert: Representative prostatospheres (PS) obtained by culturing cells in nonadherent conditions after 15 days of cultures. 
a dormant state. These CSCs may be responsible for later relapse in those patients. Interestingly, lymph-node and bone metastasis showed the lowest expression of CSCs markers. This may be explained because in growing metastasis, progenitors and malignant differentiated cells (originated from CSCs) are predominant.

Generally, prostate CSCs have been involved in EMT (Hollier et al. 2009), pre-metastatic niche preparation, relapse and metastasis (Drewa and Styczynski 2008; Kelly and Yin 2008; Takao and Tsujimura 2008). For these reasons, our results may represent an important step in the efforts to further characterize CSCs from prostate tumors in order to identify potential therapeutic targets for selective elimination. Taking into account that prostate CSCs have been studied mainly in established cell lines, we consider that our PCa explantderived culture system is more suitable as a model for the study of these CSCs. Nevertheless, the main feature of these cells is to induce tumor growth resembling the original cancer in a recipient organism. For this purpose, animal models have been widely used, but most of them are suitable to study tumor growth and local dissemination. To evaluate metastasis, orthotopic models have been developed and for PCa, human cancer lines have been implanted in the ventral prostate lobe of immuno- compromised mice, resulting in rapid tumor growth and spreading to distant organs (Celià-Terrassa et al. 2012). The main disadvantages of this model are the size of ventral lobe and the high grade of local dissemination of malignant cells. At present, we have developed a modified orthotopic model injecting PCa cells into anterior prostate lobe of NOD/ SCID mice. This model allows the surgical resection of the initial tumor and evaluating relapse and further metastasis progression. The isolated CSCs from tumor samples are been currently evaluated in this model.

\section{ACKNOWLEDGEMENT}

This work was supported by FONDECYT Grant No. 1100183. We thank Ms. Graciela Caroca for her excellent technical assistance.

\section{44}

A
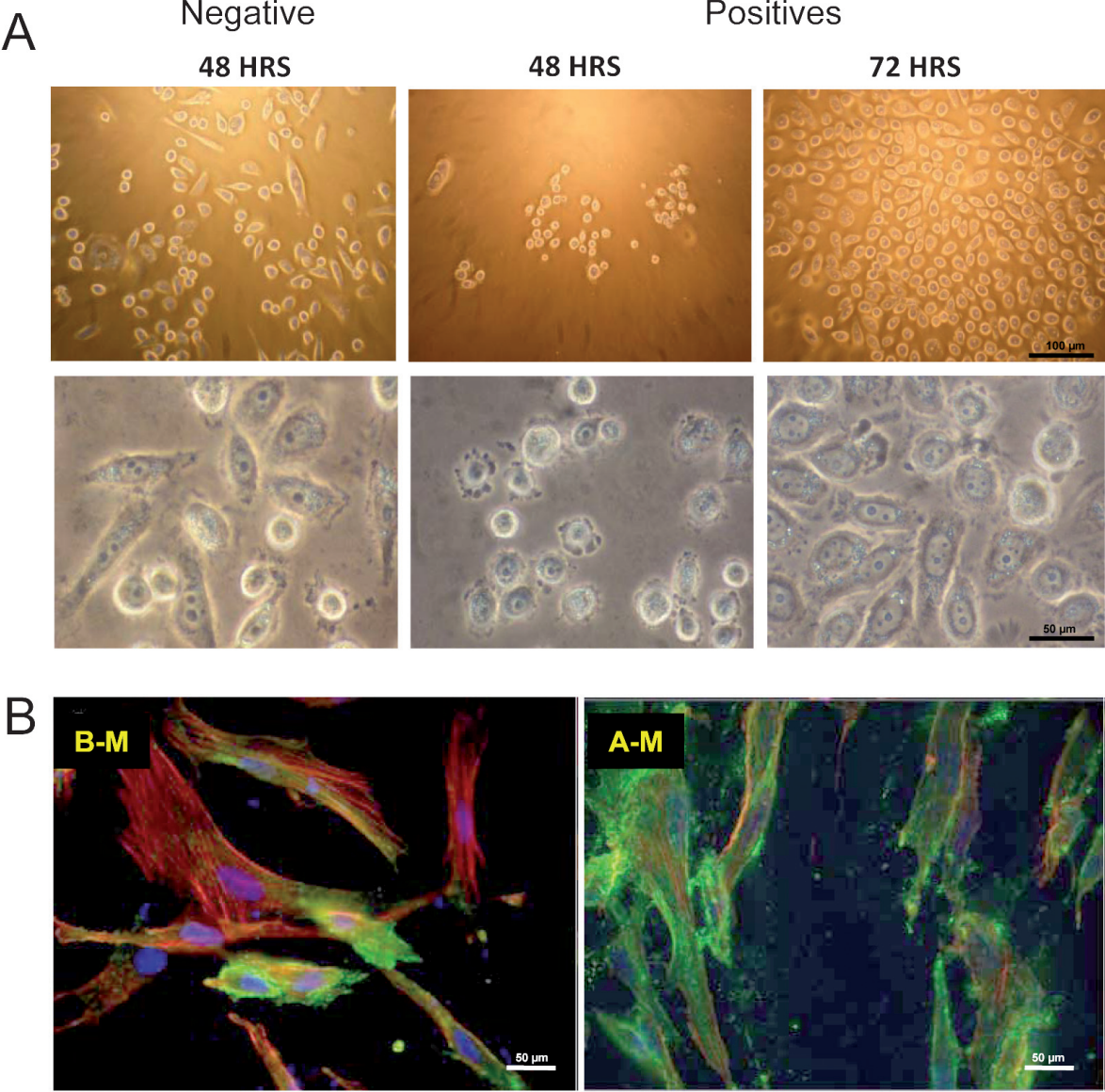

Figure 3. Representative separation of prostate cancer cells by magnetic-associated cell sorting (MACS). Enriched population of prostate cancer stem cells were processed for MACS separation using several stem marker antibody-coupled microbeads. A representative positive separation using microbeads coupled to anti-CD44 is shown. A) CD44-negative and CD44-positive cell populations 48 and 72 hrs after separation observed under the phase-contrast microscope at different magnification (see size-bars) B) Immunofluorescence analysis for CD44 (green) before MACS (B-M) and after MACS (A-M) separation. Phalloidin (red) for cytoskeleton and DAPI (blue) for nuclei staining were used. 


\section{CD $133 \quad$ CD 44}

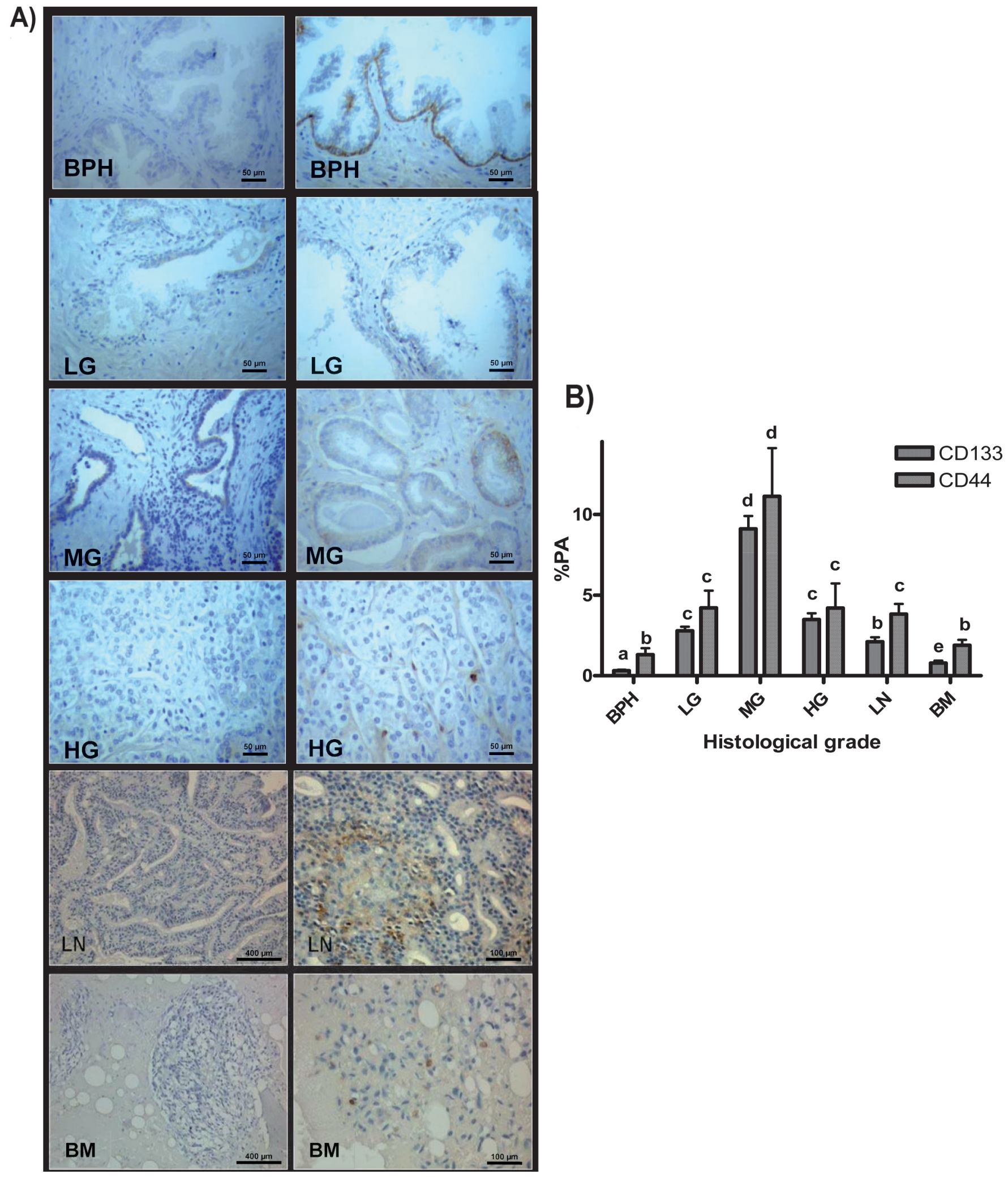

Figure 4. Immunohistochemistry analysis of cancer stem cell markers CD133 and CD44 in prostate cancer biopsies of different Gleason grades and metastasis samples. A) CD133 (left) and CD44 (right) immunostaining. BPH: Benign prostatic hyperplasia. LG: low histological Gleason grade (grade 2). MG: Medium histological Gleason grade (grade 3). HG: high histological Gleason grade (grade 4-5) LN: lymph-node metastasis. BM: Bone metastasis. See size-bars for magnification. B) Quantitative analysis of immunostaining using Image ProPlus 6.2 software. Data are expressed as percentage of positive area (PA). Different superscripts represent statistical significance $(\mathrm{p}<0.05)$. 
A)

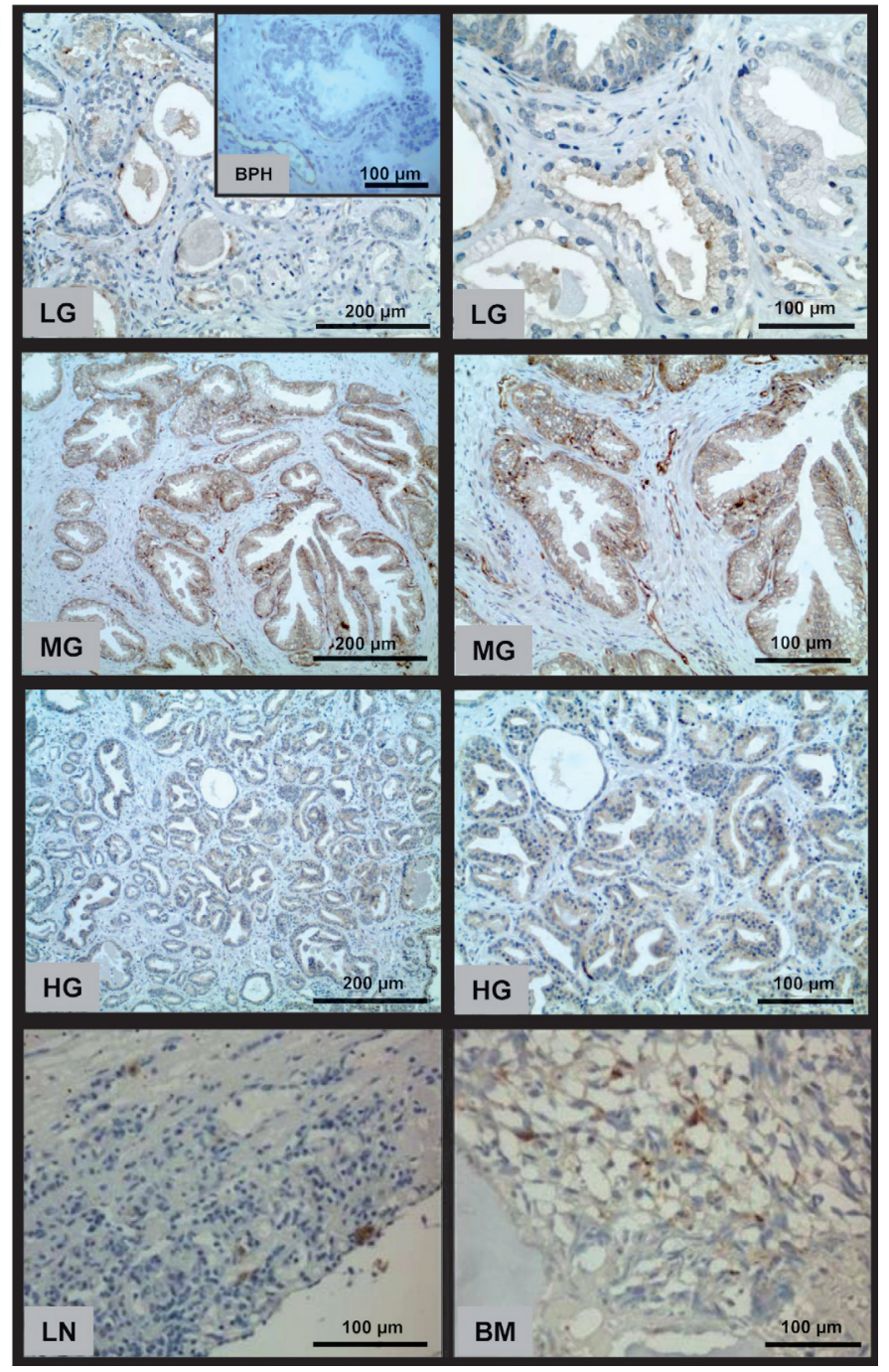

B)

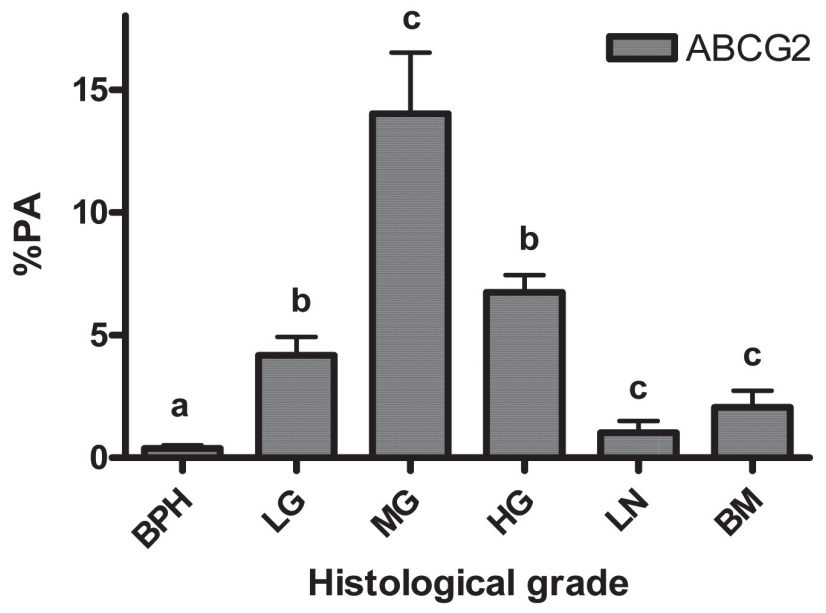

Figure 5. Immunohistochemistry analysis of cancer stem cell marker ABCG2 in prostate cancer biopsies of different Gleason grades and metastasis samples. A) ABCG2 immunostaining. BPH: Benign prostatic hyperplasia. LG: low histological Gleason grade (grade 2). MG: Medium histological Gleason grade (grade 3). HG: high histological Gleason grade (grade 4-5) LN: lymph-node metastasis. BM: Bone metastasis. See size-bars for magnification. B) Quantitative analysis of immunostaining using Image ProPlus 6.2 software. Data are expressed as percentage of positive area $(P A)$. Different superscripts represent statistical significance $(p<0.05)$.

\section{REFERENCES}

BARRANDON Y AND GREEN H (1985) Cell size as a determinant of the clone-forming ability of human keratinocytes. Proc Natl Acad Sci USA 82: 5390-4.

BONNET D AND DICK JE (1997) Human acute myeloid leukemia is organized as a hierarchy that originates from a primitive hematopoietic cell. Nat Med 3:730-37.

BORST P, JONKERS J AND ROTTENBERG S (2007) What Makes Tumors Multidrug Resistant? Cell Cycle 6:2782-87.

CABANILLAS R AND LLORENTE JL (2009) The Stem Cell Network model: clinical implications in cancer. Eur Arch Otorhinolaryngol 266:161-70.

CASTELLÓN E, CLEMENTI M, HITSCHFELD C, SÁNCHEZ C, BENÍTEZ D, SÁENZ L, CONTRERAS H AND HUIDOBRO C. (2006) Effect of leuprolide and cetrorelix on cell growth, apoptosis and GnRH receptor expression in primary cell cultures from human prostate carcinoma. Cancer Invest 24:261-68

CASTELLÓN E, VENEGAS K, SÁENZ L, CONTRERAS H AND HUIDOBRO C (2005) Secretion of prostatic specific antigen, proliferative activity and androgen response in epithetial-stromal co-cultures from human prostatic carcinoma. Int J Androl 28:39-46.

CELIÀ-TERRASSA T, MECA-CORTÉS O, MATEO F, DE PAZ AM, RUBIO N, ARNAL-ESTAPÉ A, ELL BJ, BERMUDO R, DÍAZ A, GUERRAREBOLLO M, LOZANO JJ, ESTARÁS C, ULLOA C, ÁLVAREZ-SIMÓN D, MILÀ J, VILELLA R, PACIUCCI R, MARTÍNEZ-BALBÁS M, DE HERREROS AG, GOMIS RR, KANG Y, BLANCO J, FERNÁNDEZ PL AND THOMSON TM (2012) Epithelial-mesenchymal transition can suppress major attributes of human epithelial tumor-initiating cells. J Clin Invest 122:1849-68.

CHIANG AC, AND MASSAGUÉ J (2008) Molecular Basis of Metastasis. N Engl J Med 359:2814-23.

CLARKE MF, DICK JE, DIRKS PB, EAVES CJ, JAMIESON CH, JONES DL VISVADER J, WEISSMAN IL AND WAHL GM (2006) Cancer stem cells-perspectives on current status and future directions: AACR workshop on cancer stem cells. Cancer Res 66:9339-44.

CLEMENTI M, SÁNCHEZ C, BENÍTEZ D, CONTRERAS HR, HUIDOBRO C, CABEZAS J, ACEVEDO C AND CASTELlÓN EA (2009) Gonadotropin releasing hormone analogues induce apoptosis by 
extrinsic pathway involving p53 phosphorylation in primary cell cultures of human prostatic adenocarcinomas. Prostate 69:1025-33.

COLLINS AT AND MAITLAND NJ (2006) Prostate cancer stem cells. European J Cancer 42:1213-18.

COLLINS AT, BERRY PA, HYDE C, STOWER MJ AND MAITLAND NJ (2005) Prospective identification of tumorigenic prostate cancer stem cells. Cancer Res 65: 10946-51.

CROKER AK AND ALLAN AL (2008) Cancer stem cells: implications for the progression and treatment of metastatic disease. J Cell Mol Med 12:374-90.

DEIS (Departamento de Estadísticas e Información de Salud). Defunciones, Mortalidad observada y ajustada por tumores malignos según localización, por Región y sexo. Chile 2000-2009, MINSAL, Chile.

DREWA T AND STYCZYNSKI J (2008) Can conception of prostate cancer stem cells influence treatment dedicated to patients with disseminated disease? Medical Hypotheses 71:694-99.

DUHAGON MA, HURT EM, SOTELO-SILVEIRA JR, ZHANG $X$ AND FARRAR WL (2010) Genomic profiling of tumor initiating prostatospheres. BMC Genomics. 11:324.

DUNN MW AND KAZER MW (2011) Prostate cancer overview. Semin Oncol Nurs 27:241-50.

FAN X, LIU S, SU F, PAN Q AND LIN T (2012) Effective enrichment of prostate cancer stem cells from spheres in a suspension culture system. Urol Oncol 30:314-8.

FILIP S, MOKRY J, HORACEK J AND ENGLISH D (2008) Stem Cells and the Phenomena of Plasticity and Diversity: A Limiting Property of Carcinogenesis. Stem cells and development 17:1031-38.

GAO JX (2008) Cancer stem cells: the lessons from pre-cancerous stem cells. J Cell Mol Med 12:67-96.

GIL J, STEMBALSKA A, PESZ KA AND SASIADEK MM (2008) Cancer stem cells: the theory and perspectives in cancer therapy. J App Genet 49:193-99.

GLINSKY GV (2008) "Stemness" Genomics Law Governs Clinical Behavior of Human Cancer: Implications for Decision Making in Disease Management. J Clin Oncol 26:2846-53.

HOLLIER BG, EVANS K AND MANI SA (2009) The Epithelial-toMesenchymal Transition and Cancer Stem Cells: A Coalition Against Cancer Therapies. J Mammary Gland Biol Neoplasia 14:29-43.

ISHII H, IWATSUKI M, IETA K, OHTA D, HARAGUCHI N, MIMORI K AND MORI M (2008) Cancer stem cells and chemoradiation resistance. Cancer Sci 99:1871-77.

KAPLAN RN, PSAILA B AND LYDEN D (2006) Bone marrow cells in the 'pre-metastatic niche': within bone and beyond. Cancer Metastasis Rev 25:521-9.

KELLY K AND YIN J (2008) Prostate cancer and metastasis initiating stem cells. Cell Research 18:528-37.

KOTB AF, AND ELABBADY AA (2011) Prognostic factors for the development of biochemical recurrence after radical prostatectomy. Prostate Cancer 2011:485189.

LA PORTA CA (2012) Thoughts about cancer stem cells in solid tumors. World J Stem Cells 4:17-20.

LANG SH, FRAME FM AND COLLINS AT (2009) Prostate cancer stem cells. J Pathol 217:299-306.

LAPIDOT T, SIRARD C, VORMOOR I, MURDOCH B, HOANG T, CÁCERES-CORTÉS J, MINDEN M, PATERSON B, CALIGIURI MA AND DICK JE (1994) A cell initiating human acute myeloid leukaemia after transplantation into SCID mice. Nature 367:645-48.

LE TOURNEAU C, FAIVRE S AND RAYMOND E (2008) New developments in multitargeted therapy for patients with solid tumours. Cancer Treat Rev 34:37-48

LEWIS MT (2008) Faith, heresy and the cancer stem cell hypothesis. Future Oncol 4:585-89.

LI F, TIEDE B, MASSAGUÉ J AND KANG Y (2007) Beyond tumorigenesis: cancer stem cells in metastasis. Cell Research 17:3-14.

LI H, CHEN X, CALHOUN-DAVIS T, CLAYPOOL K AND TANG DG (2008) PC3 human prostate carcinoma cell holoclones contain self-renewing tumor-initiating cells. Cancer Res 68:1820-5.

LOBO NA, SHIMONO Y, QIAN D AND CLARKE MF (2007) The Biology of Cancer Stem Cells. Annu Rev Cell Dev Biol 23:675-99.

MENDOZA P, SÁNCHEZ C, CONTRERAS HR, VERGARA J, ACEVEDO C, CABEZAS J, HUIDOBRO C, NOÉ G AND CASTELLÓN EA. (2009) Evaluation of MENT on primary cell cultures from benign prostatic hyperplasia and prostate carcinoma. Int J Androl 32:607-15.

MIKI J AND RHIM JS (2008) Prostate cell cultures as in vitro models for the study of normal stem cells and cancer stem cells. Prostate Cancer and Prostatic Diseases 11:32-9.
MIKI J, FURUSATO B, LI H, GU Y, TAKAHASHI H, EGAWA S, SESTERHENN IA, MCLEOD DG, SRIVASTAVA S AND RHIM JS (2007) Identification of putative stem cell markers, CD133 and CXCR4, in hTERT-immortalized primary nonmalignant and malignant tumorderived human prostate epithelial cell lines and in prostate cancer specimens. Cancer Res 67:3153-61.

PARDAL R, CLARKE MF, MORRISON SJ (2003) Applying the principles of stem-cell biology to cancer. Nat Rev Cancer 3:895-902.

PASCAL LE, OUDES AJ, PETERSEN TW, GOO YA, WALASHEK LS, TRUE LD AND LIU AY (2007) Molecular and cellular characterization of ABCG2 in the prostate. BMC Urol 7:6.

PATRAWALA L, CALHOUN-DAVIS T, SCHNEIDER-BROUSSARD R AND TANG DG (2007) Hierarchical organization of prostate cancer cells in xenograft tumors: the CD44+alpha2beta1+ cell population is enriched in tumor-initiating cells. Cancer Res 67:6796-805.

PATRAWALA L, CALHOUN T, SCHNEIDER-BROUSSARD R, ZHOU J, CLAYPOOL K AND TANG DG (2005) Side population is enriched in tumorigenic, stem-like cancer cells, whereas ABCG2+ and ABCG2cancer cells are similarly tumorigenic. Cancer Res 65:6207-19.

PFEIFFER MJ AND SCHALKEN JA (2010) Stem cell characteristics in prostate cancer cell lines. Eur Urol 57:246-54.

REYA T, MORRISON SJ, CLARKE MF AND WEISSMAN IL (2001) Stem cells, cancer, and cancer stem cells. Nature 414:105-11.

ROSS JS, SHEEHAN CE, FISHER HA, KAUFMAN RP JR, KAUR P, GRAY K, WEBB I, GRAY GS, MOSHER R AND KALLAKURY BV (2003) Correlation of primary tumor prostate-specific membrane antigen expression with disease recurrence in prostate cancer. Clin Cancer Res 9:6357-62

RUIFROK AC AND JOHNSTON DA (2001) Quantification of histochemical staining by color deconvolution. Anal Quant Cytol Histol 23:291-9.

SÁNCHEZ C, MERCADO A, CONTRERAS HR, MENDOZA P, CABEZAS J, ACEVEDO C, HUIDOBRO C, CASTELLÓN EA (2011) Chemotherapy sensitivity recovery of prostate cancer cells by functional inhibition and knock down of multidrug resistance proteins. Prostate 71:1810-7.

SÁNCHEZ C, CLEMENTI M, BENÍTEZ D, CONTRERAS H, HUIDOBRO C AND CASTELLÓN E (2005) Effect of GnRH analogues on expression of TrkA and p75 neurotrophin receptors in primary cell cultures from human prostate adenocarcinoma. Prostate 65: 195-202.

SÁNCHEZ C, MENDOZA P, CONTRERAS H, VERGARA J, MCCUBREY J, HUIDOBRO C AND CASTELLÓN EA (2009) Expression of multidrug resistance proteins in prostate cancer is related with cell sensitivity to chemotherapeutic drugs. Prostate 69:1448-59.

SETOGUCHI T, TAGA T AND KONDO T (2004) Cancer stem cells persist in many cancer cell lines. Cell Cycle 3:414-15.

SHAROM FJ (2008) ABC multidrug transporters: structure, function and role in chemoresistance. Pharmacogenomics 9:105-27.

SHIPITSIN M AND POLYAK K (2008) The cancer stem cell hypothesis: in search of definitions, markers, and relevance. Laboratory Investigation 88:459-63.

STAVROVSKAYA AA AND STROMSKAYA TP (2008) Transport proteins of the $\mathrm{ABC}$ family and multidrug resistance of tumor cells. Biochemistry (Mosc) 73:592-604

TAKAO T AND TSUJIMURA A (2008) Prostate stem cells: The niche and cell markers. International Journal of Urology 15:289-94.

TANG DG, PATRAWALA L, CALHOUN T, BHATIA B, CHOY G, SCHNEIDER-BROUSSARD R, AND JETER C (2007) Prostate cancer stem/progenitor cells: identification, characterization, and implications. Mol Carcinog 46:1-14.

VISVADER JE AND LINDEMAN GJ (2008) Cancer stem cells in solid tumours: accumulating evidence and unresolved questions. Nature Rev 8:755-68.

WARD RJ AND DIRKS PB (2007) Cancer Stem Cells: At the Headwaters of Tumor Development. Annu Rev Pathol Mech Dis 2:175-89.

WELS J, KAPLAN RN, RAFII S AND LYDEN D (2008) Migratory neighbors and distant invaders: tumor-associated niche cells. Genes Dev 22:559-74.

WICHA MS, LIU S AND DONTU G (2006) Cancer Stem Cells: An Old Idea-A Paradigm Shift. Cancer Res 66:1883-90.

WITZ IP (2008) Tumor-microenvironment interactions: dangerous liaisons. Adv Cancer Res 100:203-29.

YU C, YAO Z, JIANG Y AND KELLER ET (2012) Prostate cancer stem cell biology. Minerva Urol Nefrol 64:19-33.

ZHOU S, SCHUETZ JD, BUNTING KD, COLAPIETRO AM, SAMPATH J, MORRIS JJ LAGUTINA I, GROSVELD GC, OSAWA M, NAKAUCHI H AND SORRENTINO BP (2001) The ABC transporter Bcrp1/ABCG2 is expressed in a wide variety of stem cells and is a molecular determinant of the side-population phenotype. Nat Med 7: 1028-34. 
